\title{
TecHUB 4.0 - Technology and Entrepreneurship Education for Bridging the Gap in Smart Product Development
}

\author{
Mihaela Ulmeanu ${ }^{1, *}$, Cristian Doicin ${ }^{1}$, Liviu Roșca ${ }^{2}$, Allan Rennie ${ }^{3}$,Tom Abram ${ }^{3}$, and \\ Paula Bajdor $^{4}$ \\ ${ }^{1}$ University POLITEHNICA of Bucharest, Splaiul Independentei 313, 060042, Bucharest, Romania \\ ${ }^{2}$ Lucian Blaga" University of Sibiu, Victoriei 10, 550024, Sibiu, Romania \\ ${ }^{3}$ Engineering School, Lancaster University, Bailrigg, LA1 4YW, Lancaster, UK \\ ${ }^{4}$ Czestochowa University of Technology, Dabrowskiego 69, 42 201, Czestochowa, Poland
}

\begin{abstract}
Additive manufacturing is a worldwide trend and has been successfully adopted in a wide variety of domains. With applications ranging from automotive, aerospace, military, consumer goods bioprinting and even wearable electronics, the need for trained workforce in additive manufacturing is in high demand. Academia all around the world is adapting to this new trend trying to develop new strategies in delivering suitable competences to their undergraduate, masters' and $\mathrm{PhD}$ students. Such an initiative is the Erasmus ${ }^{+}$project TecHUB 4.0 which brings together four complementary universities from Romania, United Kingdom and Poland. The main goal of the project is to bring together professors, industry specialists, researchers, managers, and entrepreneurs to deliver, using methods based on modern teaching technologies, especially on the use of web-based platforms and digital technologies - e-learning and interactive platforms, their knowledge to the young students wishing to become entrepreneurs in the additive manufacturing area. An Open Interactive Platform will be designed to be used equally by companies, by universities and by students, which will aggregate the demand and offer for internships developed in the scope of developing projects anchored in the day-to-day additive manufacturing business activity to solve concrete problems, but at the same time respecting all the economic constraints imposed on a business at beginning of its life.
\end{abstract}

\section{Introduction}

Technology history shows that innovation and new business models are often developed outside the research and development departments of firms [1]. The Additive Manufacturing (AM) technologies, as a core component of the Industry 4.0 revolution, adds two key elements to the innovation: speed and customization of the products, thus facilitating the faster transformation of ideas into physical products and the transformation of users into innovators and entrepreneurs.

\footnotetext{
* Corresponding author: mihaela.ulmeanu@upb.ro
} 
Further, user manufacturers can turn into user entrepreneurs. The term user entrepreneurship has been defined as the commercialization of a new product and/or service by an individual or group of individuals who are also innovative users of that product and/or service [2].

According to Wohlers Associates [3], the global Additive Manufacturing market is expected to reach $\$ 21$ billion by 2020 . As an emerging technology spanning generations, it's vital to understand the 3D AM processes.

A survey conducted in 2016 by a print management solutions company showed that $87 \%$ of educational institutions across the world limited students' access to 3D printing [4]. The three main reasons were: educators' inability to manage and control access to the 3D printer available in the institution, educators' inability to manage $3 \mathrm{D}$ printing time and materials cost in order to allocate classroom/department expenses, as well as lack of guidance on adding 3D printing to classroom curricula. Some AM courses, as university level lectures are already available on web based platforms, but there are only a few courses on AM, and even less on business opportunities in AM. Furthermore, the majority of these courses suffer from at least one of the following drawbacks: they are not free, lectures are centred on equipment from a specific equipment/ technology vendor, the course materials are not open source, there is limited interaction between the students and the trainers, the lectures cannot be incorporated by other educators into their educational materials.

The main aim of the TecHUB 4.0 project is to diminish the aforementioned drawbacks.

Due to the broad nature of the impact of AM technologies [5], the combination of learners proposed within the project: undergraduate, masters' and $\mathrm{PhD}$ students, together with teaching staff, invited trainers and professionals is essential to supply innovative blending learning, to work in teams, and to deliver high quality education. This cross is highly relevant to European labour markets where AM know-how is expected to have a large economic impact across the continent [6]. In the same time, since the AM technologies are predicted to have a global impact, as part of the Industry 4.0 revolution [7], changing the way the society and economy operate, the transnational character of TecHUB 4.0 project is essential in a Europe with common economic and social goals.

Implementation of TecHUB 4.0 came as a natural step in the further development and improvement of existing curricula and disciplines at the home universities of the main partners. Some of the disciplines which are already delivered at POLITEHNICA University of Bucharest, both for undergraduate and masters; studies, are as follows: Product design and development, Additive manufacturing, AM technologies, Computer aided design \& Additive Manufacturing, Web services and interfaces, Sales marketing and management strategies etc. All other three partners have complementary disciplines, which are the basis for the development of TecHUB 4.0s innovative curricula.

Seen as a unique solution for blended learning, the project reaches out and fits together a variety of domains, such as: computer aided design, additive manufacturing, smart product development, technological engineering, entrepreneurship, e-business, web design etc. Delivering new hybrid disciplines using a variety of teaching tools leads to the development of vital competences in both students' and teachers' portfolio, preparing both parties to next generation's workforce market [8]. An Oxford study found that by $203347 \%$ of current existing jobs will be affected by technological change and computerisation [8], new skills and competences being required in order to be successful. In this context, the TecHUB 4.0 concept is set to develop and implement a new set of tools which promote, in particular, creative and social skills in a continuously changing technological environment. Such tools are the two intensive summer school programmes, along with the Open Interactive Platform which will be made available to the wide public and interested stakeholders. Development of skills like critical thinking, complex problem solving, creativity, team working abilities and cognitive flexibility are the main focus when 
delivering the two summer schools and throughout the development of all seven intellectual outputs of the project.

\section{Mission and Objectives}

The project addresses the development of competences involving AM technologies and technology entrepreneurship. The main focus falls on training, teaching and learning activities that better prepare the students, willing to become user entrepreneurs and innovators and the AM teaching staff at higher educational level. The project recognizes the importance of maximizing the dissemination of AM educational materials and general understanding. Therefore, the materials created in this project target also young students, familiarized only at a basic level with engineering and computers.

The project proposes three main objectives and an extended one, as described hereafter.

The first specific objective of TecHUB 4.0 relates with increasing the number of nonbusiness students - attending a technical faculty - who benefit from innovative training approaches and increasing the level of digital competences, by using a curricula that meets their learning needs and are also relevant to the labour market and societal needs, including better use of open and on-line, blended, work-based, open web-based interactive platforms, multi-disciplinary learning, and open interactive digital content, and providing more attractive training programmes, in line with individual needs and expectations and also with the new Industry 4.0 concept, focused on use of AM technologies for successful smart products development as subject of new business opportunities.

TecHUB 4.0 proposes as a second specific objective an increase in AM technologies literacy, development of relevant and high-quality competences, and entrepreneurial ability to develop start-ups starting from an idea of innovative Customized Smart Product - using AM technologies - by students enrolled at technical universities, in the context of the internationalization of activities and work within interdisciplinary and multinational teams, in a project-based learning system, emphasizing technology entrepreneurial techniques, commercialization and selling of technology based ideas, and patenting and protecting technology based ideas.

Extending the second specific objective the creators of TecHUB 4.0 aim at using AM technologies to cover broad subjects of high interest to the European community: foster employability, develop / disseminate tools for the assessment of cutting edge technical competences, as well as actions that apply "learning outcomes".

Finally, the third specific objective of the project is to develop an on-line community that actively participates in the continuous development of the digital educational materials and of AM solutions and projects, as part of Industry 4.0 revolution. Build an on-line system that transforms technology entrepreneurship education into a continuous development process, with the goal of creating an educational platform and an open source community where all intellectual outputs developed within the project are freely available.

\section{Project partners and synergy}

The project consortium is made up of four universities as follows: POLITEHNICA University of Bucharest (UPB) from Romania, Czestochowa University of Technology $(\mathrm{PCz})$ from Poland, Lancaster University (LU) from the United Kingdom of Great Britain and "Lucian Blaga" University of Sibiu (ULBS) from Romania. The four project partners were selected after a careful consideration of their vast experience in training human resources, teaching and research on AM technologies, management and entrepreneurship, in the fields of manufacturing, mechatronic and industrial engineering - all important in 
educational components, related to AM technology entrepreneurship education. The Partnership was conducted on the premise of combining the human resources and expertise of all partners involved and also the available infrastructure. The partners share a common objective: continuous improvement of training methods and creating educational and research materials for the latest AM technologies, combined with the competences on technology entrepreneurship.

LU, PCz, UPB and ULBS, as higher education institutions, have a specific educational and research focus on AM or entrepreneurship technologies. Their teaching experience brings significant value to the TecHUB 4.0 project, mainly on developing innovative educational materials. Based on the materials created, all the partners will organize workshops for learners and teaching staff.

UPB, through the Faculty of Engineering and Management of Technological Systems has considerable experience in teaching AM subjects, having the first academic labs and courses on AM in a Romanian university, and also in developing on-line collaborative learning solutions centred on technical and entrepreneurial education. This expertise in both technical and entrepreneurial domain, in building on-line educational communities, and in developing a mix of on-line and off-line events, was used in order to create a sustainable, active on-line learning community that generates valuable experiences and reputation for its participants. The faculty also has considerable practical experience as well as research publications on AM and entrepreneurship.

ULBS, through the Faculty of Engineering, comes with expertise in ICT, but also in management information systems, business modelling and simulation, business communication and e-Business. The partners' main task is to develop an open, web-based interactive platform for the creation and development of a Technology Entrepreneurship HUB. The consortium is supported by ULBS experience in this area, the partner being able to provide free and/ or open source development tools for AM and technology entrepreneurship applications. The goal of ULBS is to provide an integrated development environment for AM technology entrepreneurship education, used at large scale. The tools developed by ULBS allow beginner students to make the first steps towards creating their own AM Smart product projects, while for expert students the tools improve readability of large projects and allow fast prototyping of new ideas in order to quickly check their feasibility.

LU, through Lancaster Product Development Unit, brings to the consortium expertise in the top level research on AM technologies, being also involved in Lancaster Entrepreneurship, a centre able to guide students in their future career as user entrepreneur managing a high-tech company. Being very well situated between cutting edge technological research and entrepreneurship, the LU team provides expertise in leading the development of a Rapid prototyping guide for business development and also for the Open multimedia handbook.

$\mathrm{PCz}$, through the Faculty of Management will add the flavour of pure entrepreneurship competences. The PCz team will work to develop the digital content for the interactive platform, on management and entrepreneurship side. They will also coordinate the activities of developing the business plan road-map for the future entrepreneur engineer and will participate at all other activities requiring management and entrepreneurial skills.

\section{TecHUB 4.0 project activities}

TecHUB 4.0 implements in its 24 month timeframe the following activities: four transnational project meetings, seven multiplier events and five learning, teaching and training activities. Management, dissemination and exploitation of the project results are 
not considered a part of the abovementioned activities and are dealt with separately by all team members.

\subsection{Transnational project meetings}

Since the project involves the continuous transfer, exchange of information and guidance, all project partners (represented by at least one member) will meet face to in activities called transnational project meetings. The general agenda of these meetings comprises of unsolved tasks and special issues that need to be brought to the attention of all the partners for a consensual decision. Four transnational project meetings are scheduled throughout the implementation period of TecHUB 4.0, one at the premises of each partner. The four meetings are planned so as to ensure a pro-active project management plan implementation strategy and provide continuous development of activities and intellectual outputs. The first project meeting (Fig. 1) took place at the premises of the coordinator and entailed discussions and presentations about the detailed workplan, financial targets, outputs and specific partner tasks, dissemination strategy, future agenda, paperwork and reporting procedures.

For a smooth cooperation between the partners and the project manager, the meeting are organized so that the interval between two consecutive ones to be approximatively constant, ensuring in this way the timely transmission of technical and financial documentation needed for the reporting system.

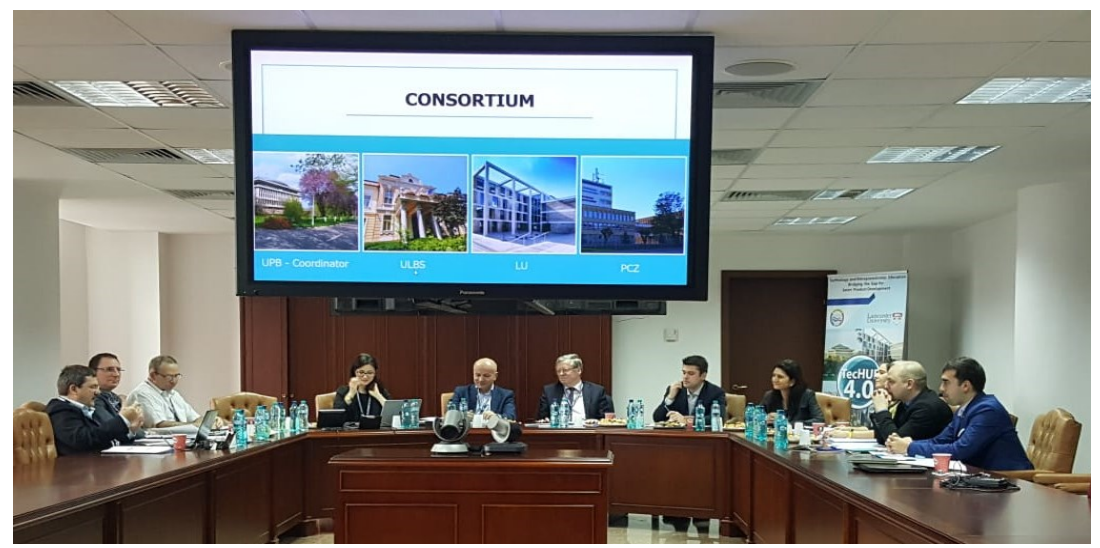

Fig. 1. First transnational project meeting at UPB - December 2018

\subsection{Multiplier events}

In order to support an efficient dissemination and exploitation strategy, seven multiplier events have been defined within the projects' scope, namely: E1 - Technology transfer in AM (organised at the premises of UPB); E2 - Trends in entrepreneurship education (organised at the premises of PCz); E3 - Smart Product Development and Digital Manufacturing (organised at the premises of PCz); E4 - Technology entrepreneurship through interactive learning (organised at the premises of UPB); E5 - Trends in IoT Education: Smart Products (organised at the premises of ULBS); E6 - Additive Manufacturing Technologies in Product Design and Development for Manufacturing Companies: Adoption Rate and Benefits (organised at the premises of LU); E7 - Open Interactive Platform - Entrepreneurship Hub (organised at the premises of UPB). Each individual multiplier event is set to transfer specific project results from the seven 
intellectual outputs $(\mathrm{O} 1 \div \mathrm{O} 7)$ to interested stakeholders, as follows: E1 disseminates outputs $\mathrm{O} 1$ and $\mathrm{O} 7$; E2 disseminates outputs $\mathrm{O} 2, \mathrm{O} 3$ and $\mathrm{O} 5$; $\mathrm{E} 3$ disseminates outputs $\mathrm{O} 3$ and $\mathrm{O} 5$; E4 disseminates outputs O3, O5, O6 and O7; E5 disseminates outputs O6 and O7; E6 disseminates outputs $\mathrm{O} 4$ and $\mathrm{O} 7$; E7 disseminates output $\mathrm{O} 7$.

The purpose of all seven multiplier events is to describe and popularize the outputs and the application concerning entrepreneurship education constructed in TecHUB 4.0 project to national and international partners of the host organizing institution.

\subsection{Learning, teaching and training activities}

Five learning, teaching and training activities are proposed to be implemented within the timeframe of the project. The main proposed activities are the following: $\mathrm{C} 1$ Workshop on 3D Printing in Smart Product Design and Development, organised as a shortterm joint staff training event by Lancaster University at the premises of their location; C2 $1^{\text {st }}$ Intensive Summer School, organised as an intensive programme for higher education learners by UPB at their premises and hosting student 100 participants; C3 - Workshop on Entrepreneurship Education - Start-ups \& Spin-Offs in Technology, organised as a shortterm joint staff training event by $\mathrm{PCz}$ it will host 35 participants amongst which two UPB team members; C4 - Workshop on Smart Manufacturing, hosted by ULBS as a short-term joint staff training event at their university premises; C5 $-2^{\text {nd }}$ Intensive Summer School, activity hosted by UPB as an intensive programme for higher education learners.

LU organised the first short-term joint staff training event, $\mathrm{C} 1$ as an interactive workshop on 3D printing in smart product design and development (Fig. 2).

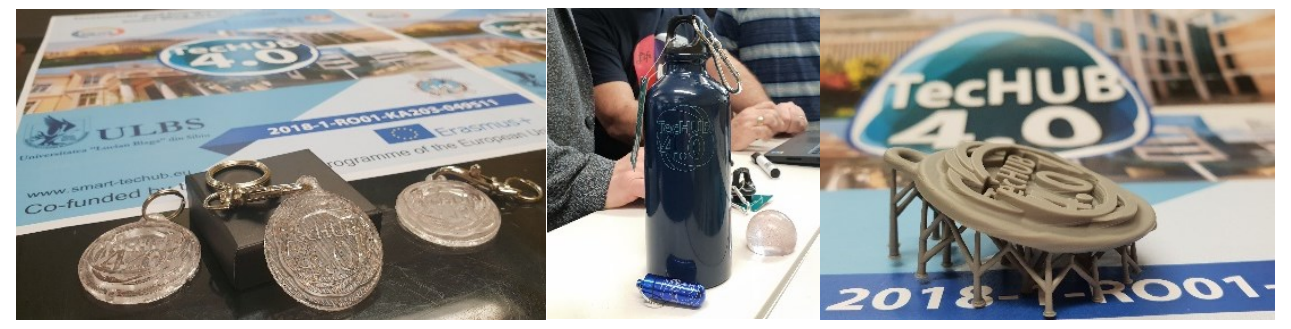

Fig. 2. Applications developed during the C1 Workshop on 3D Printing in Smart Product Design and Development organised by LU - April 2019

These learning activities are essential to the project's objectives and to guarantee the quality of the intellectual outputs. The learning activities are intended to serve six specific purposes, as follows: 1. Educational materials will be tested in a real-world scenario with actual students/educators; Feedback collected during these workshops is integrated in the educational materials; This feedback loop is an invaluable part of creating, revising and validating the educational materials, guaranteeing their quality; 2. Video recordings will be taken and posted on the on-line platform when the educational materials in developed in several of the projects' outputs will be used; This will serve future educators who want to use the educational materials in order to see an example of a real-world delivery of the class; 3. Since the teaching activities take place at partner institutions in several countries we are able to evaluate the European character of the educational materials created; This is essential in order to establish the global character and impact of the project; 4. A direct result of these workshops is the training of students/educators in basic and advanced AM technologies; Therefore, the project also contributes directly to the increase in AM literacy and of the number of AM experts; An estimate of 931 students/ educators will benefit in this direct fashion from the project; 5 . The activities serve a special purpose for the partners 
involved in the advanced AM and ICT applications modules to get hands-on practice with the particular nature of their target technologies; This is an essential component for guaranteeing the quality and the feasibility of the advanced AM applications developed; 6 . The AM technological entrepreneurship projects created by the participants to the workshops will be uploaded on the on-line platform; This will ensure an initial, critical mass of contributions to the $\mathrm{AM} /$ technological entrepreneurship online community the project aims to create, thus increasing the popularity of the online platform and encouraging others to publish AM technological entrepreneurship projects themselves.

The two intensive summer schools organised by the project coordinator are seen as a way of putting together all the teaching materials and educational tools created within the TecHUB 4.0 framework, testing and improving them for public use. During the course of the summer schools all intellectual outputs are scheduled to presented and tested on real-life scenarios. Multi-disciplinary projects will be created around the content of the intellectual outputs, accompanied by best-practice examples, case studies, interactive pop-up technology fairs and workshops, all of which will reflect the project results. An alfa version of the Open Interactive Platform will be tested in the first summer school, a beta version during the second summer school and the final version will be finalised in time for the last multiplier event in order to ensure an effective transfer of knowledge to relevant stakeholders. Blended learning will focus on four main areas of interest: Design for Additive Manufacturing, Product Design and Development, Entrepreneurship and business, Web design. During the two summer schools 100 participants (undergraduates, masters; and $\mathrm{PhD}$ students) will be divided in teams and will be required to construct and present a start-up type project by the end of the proposed timeframe. Some of the tasks they will need to perform in an organised international environment are: workload distribution amongst team members; description of a company; pin point a specific aim and company objective; develop a team structure; describe services and products; design and manufacture using 3D printing a product line comprised of at least 10 products; develop a business plan; propose a financial strategy; design a logo and a marketing campaign; design a company website, complete with on-line store; deliver a ten minute presentation etc. Activities and contents are prepared and delivered so as to create vital competences in technology entrepreneurship and develop soft skills. In order to motivate students and get them engaged in all activities they will be presented with the opportunity to keep all developed and 3D printed products, along with all provided teaching materials. Invited lecturers are set to give interactive learning experiences in the form of hands-on technology presentations and interactive seminars on smart products, IoT and technological entrepreneurship.

An international environment is set to be created by selecting participants from three of the consortium partners. Erasmus students will also be encouraged to participate in the programmes. In order to improve the blended learning program, at the end of the learning activity participants will be asked to complete a feedback form, as well as construct a SWOT analysis about the learning experience.

\section{TecHUB 4.0 project results and sustainability}

Seven intellectual outputs will be developed within the projects; framework: O1 Comprehensive study on technology transfer in the additive manufacturing industrial environment through technology entrepreneurship education methods; O2 - Business Plan Road-map for the future engineer as an entrepreneur; O3 - Curriculum Workbook for Intensive Summer Training Course - Technology Entrepreneurial thinking for bridging the gap between Education, Technology Research and the Business environment; O4 - 3D Printing Guide for Successful Business Development; O5 - Training program and Open elearning content for transferring research and innovation into the industrial environment 
through entrepreneurship education; O6 - Open Multimedia Handbook for project based learning of technology entrepreneurship for HE students and SME trainees; O7 - Open interactive platform for creating and developing a Technology Entrepreneurship Hub, by Transferring Research and Innovation in the industrial environment. All intellectual outputs developed within TecHUB 4.0 project will be used to deliver the learning, teaching and training activities within the project.

The results and outputs of TecHUB 4.0 will be transferred to regional, national, European and international levels by the on-line platform and community that the team members develop. The platform is created so that the access to the educational materials is easy and interaction is natural at all technical levels, in English language, being designated to students who are studying in English language (but not exhaustive) at each of the partner universities and also to Erasmus students and all the user communicating in English language. At the European level the desired impact consists of enlarging, in numbers and vision, the number of persons aware of the huge possibilities of the AM technologies, by acting so to: 1. increase the number of the students informed about the AM technologies and also number of AM specialists; 2. increase the number of students who interact with modern AM technologies and with the opportunities of starting a business using the AM technologies; 3. establish an international uniform level of knowledge on AM technologies and education by providing a broad range of educational materials; 4. enlarge the technical horizon and employment options of students and youth, in general; 5. highlight the benefits that AM technologies can bring to several open problems European societies need to tackle such as: environmental issues, power managements, privacy and information security; 6 . ensuring AM technologies know-how levels are uniform, at a high level, across the European Union, all the documents being developed in English language.

Digital educational materials will be continuously available for download even after the end of the project. They will be maintained on open source, free repositories (such as for video and source code content for example) that do not delete any content for the foreseeable future. The capability to upload/share/download/customize projects on the online AM community platform will be continued also after the end of the project. The authors consider this feature central to the continuous AM professional development of the platform's users. The digital materials available are developed in several ways: • Developed voluntarily by users (students and teachers) that have specific educational needs (eg. the addition to the materials of new modules dealing with a particular branch of AM technologies); - New developments can also be supported by new project funding from various agencies; - Professors can use the educational materials in their AM courses or workshops and continuously adapt them to new teaching situations, examples and applications. This ensures the long term development of the materials and their sustainability. Ultimately, the sustainability of TecHUB 4.0 heavily depends on the quality of the materials and services provided. For this reason, during the project, emphasis is put on quality control and continuous development of the materials resulting from feedback and proactive initiatives.

\section{Conclusions}

TecHUB 4.0 project is innovative in that it advances the state-of-the-art in AM and technology entrepreneurship education by combining top-level learning materials, with the power of collaborative communities, project based learning, blended learning and open platform with digital e-learning content.

The ultimate goal of the project is to set up, around a set of core open educational materials, an open on-line community that continuously contributes to AM technology entrepreneurship education. Constructed on the concept of crowd knowledge, the project 
will create an interactive on-line platform where people (learners, teaching staff, specialists from industry etc.) will contribute, evaluate and share their AM expertise and applications. This way, they will interact in a continuous and dynamic way with the educational materials, increasing their efficacy. This sustainable way of constructing an educational platform will offer on the long term a fast development due to a large number of contributors, an increased quality of the materials provided due to the permanent feedback, flexibility and scalability due to the diversity of the contributors.

Practice is an important aspect of the educational process and therefore the materials created within the project will combine theoretical notions with tutorials and examples on both dimensions, technological and entrepreneurial, allowing students to apply everything they learn and consolidate their knowledge, in an interactive way, as another innovative aspect of the project.

The project aims to create a foundation consisting of written and interactive materials which can be extended to create courses both for advanced students with a technical knowledge base, but also for students who make their first contact with the AM field through this hands-on experience. The on-line community is developed around the open interactive platform filled in with digital content.

Courses will introduce students to state-of-the-art technologies, which they will use to create projects on Smart product development, as part of their future integration in an Industry 4.0 world. A beginner in the AM field will find a level of abstraction high enough, that permits non-experts to create new AM start-ups and to modify and tweak existing solutions according to their needs and use cases.

Acknowledgement: Erasmus+ Project Nr. 2018-1-RO01-KA203-049511, "TecHnology and EntrepreneUrship Education - Bridging the Gap for Smart Product Development" - TecHUB 4.0, $2018-2020$.

\section{References}

1. E. Von Hippel, Democratizing Innovation, Cambridge, MIT Press, ISBN 0-262-00274-4 (2005)

2. S. Shah, M. Tripsas, SEJ, 1, 123-140 (2007)

3. T. Wohlers, Wohlers Report 2018, ISBN 978-0-99133332-4-0 (2018)

4. Y Soft, Global survey on $3 D$ printing in the Education sector, (2017), available at: https://www.ysoft.com/pl/company/newsroom/press-releases/2017/y-soft-global-survey-claims87-of-educators-restr

5. J. Zhang, Y.-G. Jung (Editors), Additive Manufacturing: Materials, Processes, Quantifications and Applications, Elsevier, ISBN 978-0-12-812155-9 (2018)

6. E. Pei, M. Monzón, A. Bernard (Editors), Additive Manufacturing - Developments in Training and Education, Springer, ISBN-10: 9783319760834 (2019)

7. U.M. Dilberoglu, B. Gharehpapagh, U. Yaman, M. Dolen, Procedia Manufacturing, 11, 545-554 (2017)

8. C. B. Frey, M.A. Osborne, Technol Forecast Soc, 114, 254-280 (2017) 